\title{
THE HAPPY YOUTH OF A DESPERATE COUNTRY: THE DISCONNECT BETWEEN JAPAN'S MALAISE AND ITS MILLENNIALS, by Noritoshi Furuichi (Japan Publishing Industry Foundation for Culture, Japan, 2017)
}

\author{
OTGONBAATAR TSEDENDEMBEREL ${ }^{1}$
}

In this book, with its seemingly self-explanatory title, Noritoshi Furuichi argues that, despite Japan's desperate situation amidst decades-long economic recessions, a deteriorating birth rate, an ageing population, the immediate aftermath of the Great East Japan Earthquake of March 11, 2011, and the subsequent Fukushima Daiichi nuclear disaster, the majority of its youth (nearly 80 percent) seem to be "happy" nonetheless. Noritoshi Furuichi is a young Japanese sociologist, a senior researcher at the Keio Research Institute, a Ph.D. candidate at the Graduate School of Arts and Sciences of the University of Tokyo, and a dedicated commentator on youth and political issues. Zetsubo no kuni no kōfuku na wakamonotachi (the Japanese title of the book) reports how Japanese youth deal with desperation and despair in their own terms based on the author's articulations of youth theory, various interviews with young people, an extensive review of government surveys and publications, as well as his own observations as a sociologist and a young member of Japanese society.

The book is unique in the sense that it documents young people's reactions and moods right after the 3/11 natural disaster, reflecting the aspirations and frustrations of youth. At the same time, it is a book about youth by a young scholar who has thought much about youth theory and youth issues and debates with the former through multiple channels, including on Japanese television. This book is original and novel because Furuichi critically analyzes what it means to be a youth or young in today's Japan with its challenging political, social, economic, and cultural realities. The 2015 paperback edition and the much-needed English translation of 2017, comprised of over 280 pages, are empirically-informed, scholarly, yet very enjoyable books on youth theory

1 Otgonbaatar Tsedendemberel is a Ph.D. student at the Doctoral School of Sociology, Corvinus University of Budapest, e-mail: otgonbaatartsedendemberel@hotmail.com. 
by a youth; Furuichi himself was only twenty-six years old when he released the original book in 2011. Writing extensively about topics such as the war museums of the world, with an analysis of the intersection between war and memory, generation-gap-related issues, and women's solutions to childcare, Furuichi's other books include Nobody Can Teach War, Kodansha, 2015; That's Why Japan is Off, Shinchosha, 2014; and Making Nursery Schools Compulsory; Shogakukan, 2015.

The title of the book is neither self-explanatory nor misleading, as the author challenges and unpacks common assumptions and (mis)perceptions that have to do with young people in Japan. Furuichi speculates, contrary to common belief, that those who lived and worked hard during the period of high economic growth of the 1980s were not necessarily "happy" given the extended working hours required from young employees who joined the infamous "rat race" characterized by a post-war modern business management model ("the good school, the good company, the good life") and the excessive competition involved in entering university of high school pupils, as represented in the so-called "exam wars." Compared with these arguably miserable, "misfortunate" lives led by their counterparts of more than 30 years ago, the "happy" youth of today enjoy the effects and products of highly developed information and technology, benefit from reasonably accessible, available, and affordable services in terms of food, shelter, and clothing, participate in neo-liberal capitalist consumerism, and are presented with abundant life choices and opportunities. Furutoshi claims that young people are "happy" and satisfied with the present because "they do not believe that tomorrow will be better than today."

Through this book the author attempts to start a dialogue by looking into the essence and dynamics of contemporary youth in his society, but, more importantly, fills in the gaps in the youth-related arguments and theories proffered thus far. In six chapters, the author aptly questions the meaning of "young people" as an entity, concluding that the expression is merely an illusion based on his conversations and analysis of youth discourse; he also demystifies various perceptions and stereotypes surrounding youth through a rigorous review of survey data; presents fieldwork findings with a special focus on events such as the World Cup and youth participation in protests and demonstrations; and discusses generational disparities and problems with labor. Addressing the hope and anxiety, satisfaction and dissatisfaction, as well as dreams and despairs of youngsters in tough times is not unique to Japan; just as financially challenging circumstances gave rise to the phenomenon of "parasite singles" in Japan - young people who live with their parents beyond their late twenties - equivalent terms emerged in other developed nations, such as twixter in the United States, nesthocker in Germany, and mammoni in Italy. 
Youth theory, or theorization about the young people of Japan (seinen-ron) itself, should be a part of the famous Nihonjin-ron arguments (theories and discussions about the allegedly common traits of the Japanese), but youth discourse is largely absent of this umbrella theory. Or rather, as the author suspects, youth discourse merely serves as a means for adults to enrich the overall Nihonjin-ron. In this sense, Furuichi establishes that we should consider the particular phenomenon not as an issue that concerns individual young persons but as one that should be understood together with the realities of the existing social structure. This brings the author to iterate the purpose of his book: "to structurally portray as social issues the issues of 'young people,' which are prone to being appropriated - that is to say, co-opted - for personal identity purposes and cultural matters." Having defined the theoretical or conceptual frameworks with regard to the "young people" under discussion, Furuichi tackles the empirical data in the subsequent chapters and refutes a series of myths surrounding young people: they are not necessarily "inward looking"; they are not reluctant consumers, but they consume carefully; although young people do not show up to cast their votes at the ballot box, they are politically active in terms of participating in protests and relief campaigns. Methodologically, the author sees the Public Opinion Survey on Social Awareness as an excellent source as it has been asking same questions for more than thirty years, making it possible for researchers to analyze shifting attitudes.

Furuichi tackles youth theory from four major perspectives: "alien others," "expedient allies," "cultural argument," and "empirical studies," in which he argues that the older generations' bashing of young people as "alien others" has been ongoing for more than a century, whereas the wartime period saw young people prominently being viewed as "expedient allies." However, modern youth discourse started together with the so-called "fantasy of the classless society" in which young people were discussed as if they all came from the middle class, glossing over their local differences, economic disparities, and gender. Therefore, the author focuses his analyses and arguments on young people in their twenties who lived in the immediate aftermath of the period of economic growth that ended in 1991. With the bursting of the economic bubble, which started in the 1970s, "the good school, the good company, the good life" model, consequent life-time employment prospects and related guarantees for life collapsed at the same time. The lost decades, which stretched from 1991 until 2011, are well-known as a time of prolonged economic recession(s) in Japan which saw the 3/11 earthquake and nuclear disaster at the end. Thus, this is the story of how Japanese young people have been dealing with such a desperate climate and dark clouds over their heads. 
Central to the author's main arguments is his attempt to redefine what it means to be young - youth theorization. Whereas the term "wakamono" (young people) refers to those in their twenties and thereabouts, "seinen" (youth) means the young generation, a term which was commonly used until the 1970s. The former replaced the latter due to the undesirable normative nuances expressed by the latter. In claiming that "young people are our/nation's hope" or that "young people these days are [such and such] (usually negative adjectives or connotations)," adults impose high expectations on youth as a group, or "youthbash" or blame them for just being themselves. Young people, while required to be patriotic and nationalistic, and often glorified in the media and by an integral part of society, are also considered expendable as they were required to sacrifice their lives for the country, first during times of war (from the second SinoJapanese war to WWII) and then for the so-called economic war. In discourse, it appears that life for Japanese youth is often characterized as a "war," ranging from a real war to the "rat race" to achieving well, financially and collectively (an "economic war"), and to performing well academically and individually ("exam war"), to climbing up the increasingly crucial social, economic, academic, and professional ladders. Youth discourses about post-war democracy and postWWI liberalism, especially the criticisms expressed by the older generations, are painfully similar to how some post-Soviet countries criticize their youth for interpreting democracy as "anarchism," and human rights and gender issues as "unacceptable ideologies."

In other words, from being the "nation's hope," "consumer" citizens, warriors in all sectors of life, to "outrageous" in the eyes of adults, "capsule beings," or "moratorium beings," young people as a whole and as a generation are portrayed as either "alien others" or "expedient allies." Youth are seen as a hope and "ally" one day and "alien others" the next, being subjected to the mood and the sway of adults. Furuichi is overly critical of the dangerously harmful term "generationalism," as it tends to overlook the individualistic and hierarchical diversity inherent in a "generation," and neglects all other signifiers such as race, gender, and community. Moreover, there are cultural arguments that contribute to the emergence of the siloed, individualized wakamono. Along with strong economic growth, the first baby boomers who were born between 1947 and 1949, and those who have not experienced war, created their own unique culture, further complicating the definition of young people as an entity. On the other hand, the culture of copycat (replicated) experiences afforded by the information society of the mid-1970s made young people "together-separate," united through distant "experiences," similar to today's online culture in which young people of all societies connected through the internet can have common, shared experiences despite space, time, and location. Thus, the concept of 
wakamono emerged somewhere between the late 1960s and the 1970s to define a homogenous group whose attributes other than age did not matter. Therefore, the author avoids employing a single, unified definition of "youth," or "young people" in this book, let alone deploying today's commonly used definitions of youth created by international organizations such as the United Nations (UN) and other similar institutions.

Apart from the signifiers such as race, gender, age, and community, another dimension which enriches the arguments in the book is class. The 1960s, along with post-war economic growth and media representations of youth, witnessed the fantasy that the class system had been abolished altogether, wherein people mistakenly thought that Japan had become a classless society, evidenced by the "one-million-member-middle-class" myth. In this, age was the only thing people focused on, while expressing disillusionment that all young people were from the middle-class, whereas in reality disparities still existed. The author is understandably and justly skeptical about the notion of "youth as customer" and the "ichi-oku sō-churyu" myth ("one-million-member-middle-class" myth) which is still relevant and valid today given the recent advent and promotion of a minimalist culture among youth, both in developed and developing countries.

Of relevance to the field of sociology, it is intriguing to discover that in 1953 the first full-scale sociological study of young people in Japan reviewed the then-available research on youth in Europe and America, applying it to concrete cases observed in the country. In this study, a group of Japanese sociologists discussed seinen as a generation, a diverse entity, through a compilation of scholarly essays. Unlike how some contemporary psychologists viewed youth as a "biological generation" and thus those of urban and rural environments as one and the same, sociologists, focusing on the social relevancy and social disparity of youth, decided otherwise. On the other hand, Furuichi confesses that his understanding of the modernization of Japan shifted from a "textbook understanding" to a better place following the launch of a book by the 85-yearold sociologist Hidetoshi Kato in 2015, Media no tenkai ("The development of media"). Whereas Furuichi had thought the Edo period (1603-1868) was "premodern," Kato's claims proved that it was "early modern" in the sense that by the mid-eighteenth century changes deemed to be the signs of "modern times" were already underway. An example of this is the mass tourism that started at that time, refuting some misperceptions that the freedom of movement was then altogether prohibited.

Although Furuichi succeeded in starting and intensifying the debate about youth in Japan with his book, he also was able to promote inter-generational dialogue among sociologists and social scientists. One of the formidable examples of this has been presented above. Throughout the whole book, 
Furuichi meticulously details the age and hometown of each and every author he references, the young people he interviewed, and even foreign authors and scholars he quoted both in and off text in brackets. This might validate some readers' prejudices about the thoroughness and meticulousness of the Japanese. However, these minor references help readers to follow who proposes or opposes which arguments, and where these individuals might have come from in terms of age and background. Not that it matters a lot, but it is a helpful tool.

Furuichi proposes and backs up many fascinating arguments to full satisfaction with the relevant empirical data in a true sociological sense. To experience this pleasure, readers should choose this book - either the Japanese or English edition - in anticipation that the adept, skillful translation does not lack the sarcastic and ironic tone and caustic wit of the author in either language. More importantly, the book is a living document as the author has been able to update the content, to converse with himself and other contributors and scholars, as well as his critics, since the first launch and paperback edition of the book. In sum, Furuichi, by re-defining and problematizing the notion of youth in today's Japanese society as an illusion but a diverse entity, critically questions how young people as a whole can contribute to society by seeking ways to solve some of the social, economic and political dilemmas involved with this desperate situation. Endorsed by empirical data and sound analyses that are both based on research findings and in-depth interviews and observations, the author presents possible interpretations of consummatory or self-sufficient young individuals who are somewhat satisfied with their way of living, but increasingly anxious and adamant about where all this is leading. 